\title{
Embryonic Heart Progenitors and Cardiogenesis
}

\author{
Thomas Brade ${ }^{1,5}$, Luna S. Pane ${ }^{1,5}$, Alessandra Moretti ${ }^{1,2}$, Kenneth R. Chien ${ }^{3,4}$, \\ and Karl-Ludwig Laugwitz ${ }^{1,2}$ \\ ${ }^{1}$ Klinikum rechts der Isar, Technische Universität München, I. Medical Department, Cardiology, 81675 Munich, \\ Germany \\ ${ }^{2}$ DZHK (German Centre for Cardiovascular Research), Munich Heart Alliance, Munich, Germany \\ ${ }^{3}$ Karolinska Institutet, Department of Cell and Molecular Biology and Medicine, Berzelius Vag, Stockholm, \\ Sweden \\ ${ }^{4}$ Harvard University, Department of Stem Cell and Regenerative Biology, Cambridge, Massachusetts 02138 \\ Correspondence: thomasbrade@gmx.de
}

The mammalian heart is a highly specialized organ, comprised of many different cell types arising from distinct embryonic progenitor populations during cardiogenesis. Three precursor populations have been identified to contribute to different myocytic and nonmyocytic cell lineages of the heart: cardiogenic mesoderm cells (CMC), the proepicardium (PE), and cardiac neural crest cells (CNCCs). This review will focus on molecular cues necessary for proper induction, expansion, and lineage-specific differentiation of these progenitor populations during cardiac development in vivo. Moreover, we will briefly discuss how the knowledge gained on embryonic heart progenitor biology can be used to develop novel therapeutic strategies for the management of congenital heart disease as well as for improvement of cardiac function in ischemic heart disease.

$T^{1}$ he functional heart is comprised of diverse muscle and nonmuscle cell lineages: atrial and ventricular cardiomyocytes, endocardial cells, valvular components, and connective tissues, conduction system cells, as well as smooth muscle and endothelial cells of the coronary arteries and veins. Understanding the molecular mechanisms that drive the specification of these cell lineages from naïve progenitor populations into terminally differentiated cell types within the four-chambered embryonic heart is of fundamental importance to elucidate the pathological mechanisms underlying congenital heart disease and to improve management of ischemic heart disease (Olson 2004; Srivastava 2006). Three spatially and temporally distinct sources of heart cell precursors have been identified in the embryo: cardiogenic mesoderm cells (CMCs), the proepicardium $(\mathrm{PE})$, and cardiac neural crest cells (CNCCs) (Fig. 1A-C).

The cardiogenic mesoderm, which harbors the so-called first and second heart fields (FHF and SHF), forms the major proportion of the ventricular, atrial, and outflow tract (OFT) myocardium. Additionally, these progenitors contribute cells to the endocardium, the conduction

${ }^{5}$ These authors contributed equally to this work.

Editors: Margaret Buckingham, Christine L. Mummery, and Kenneth R. Chien

Additional Perspectives on The Biology of Heart Disease available at www.perspectivesinmedicine.org

Copyright (C) 2013 Cold Spring Harbor Laboratory Press; all rights reserved; doi: 10.1101/cshperspect.a013847

Cite this article as Cold Spring Harb Perspect Med 2013;3:a013847 
T. Brade et al.
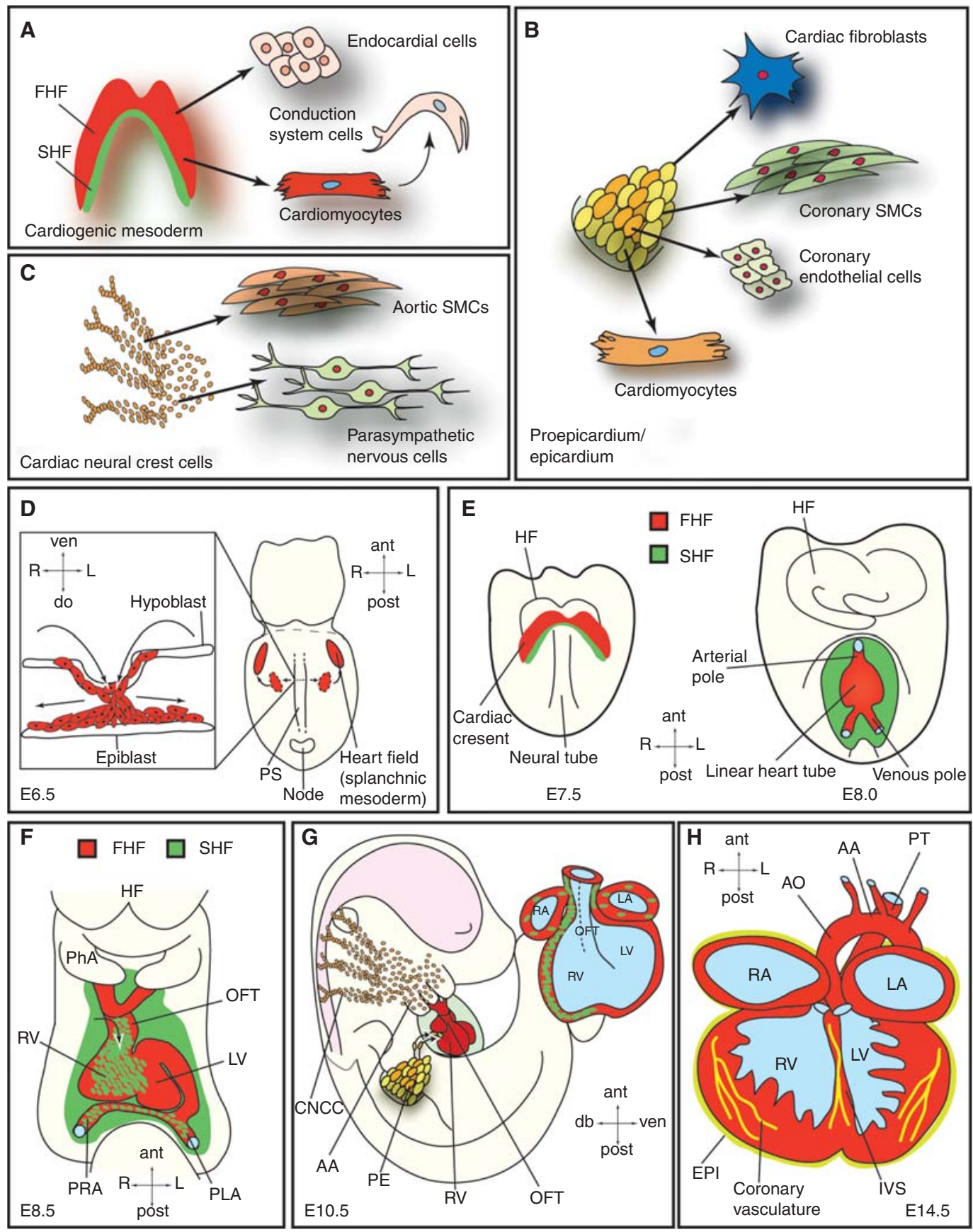

Figure 1. Embryonic heart progenitor contributions to different cardiac compartments and cell types during heart morphogenesis in mouse development. (A) Cardiogenic mesoderm, (B) proepicardium/epicardium, and $(C)$ cardiac neural crest cell lineage diversification. $(D)$ At E6.5, mesodermal progenitors ingress through the primitive streak (PS) and migrate away from the PS (illustrated in the box showing a transverse section) to form the heart fields located in the splanchnic mesoderm. (E) At E7.5, the first and second heart fields (FHF and SHF) are discernible. The first heart fields fuse at the midline thereby forming the cardiac crescent caudal to the headfolds. FHF progenitor cells start to differentiate. (Legend continues on facing page.) 
system, and the aortic and pulmonary cushions (Fig. 1A).

Progenitors originating from the PE comprise the epicardium and differentiate into interstitial fibroblasts embedded in the myocardium, vascular smooth muscle cells and endothelial cells of the coronary vessels, and some myocytes, mainly in the atrioventricular septum. Additionally, interaction of the epicardium with the underlying myocardium is crucial for chamber maturation and ventricular muscle growth (Fig. 1B).

Finally, the CNC progenitors give rise to the distal smooth muscle cells of the OFT and the aorticopulmonary ridge as well as to the autonomous nervous system of the heart. Cardiac valve development and septation of the heart is also critically dependent on proper $\mathrm{CNC}$ development (Fig. 1C).

Here we will describe "the lives" of these different cardiac progenitors, from their embryonic specification to their differentiation into mature cells of the heart, and we will discuss how this knowledge could inform the future development of novel therapies for cardiovascular heart disease.

\section{THE CARDIOGENIC MESODERM PROGENITORS}

Cardiogenic Mesoderm Progenitors in Early Vertebrate Cardiogenesis

The embryonic heart is the first organ to function during development. Fate mapping studies in mouse and chicken embryos have shown that time and location of cell ingression through the primitive streak (PS) (Fig. 1D section detail in box) determines the fate of gastrulating cells.
Embryonic Heart Progenitors and Cardiogenesis

Consequently, cardiac mesoderm progenitors are among the first cells to ingress through the PS during gastrulation. These naïve cardiogenic mesoderm cells migrate away from the PS and coalesce in an anterior lateral region relative to the streak, the so-called splanchnic mesoderm (Fig. 1D), where they form the cardiac crescent (at mouse embryonic day E7.5, corresponding roughly to week 2 of human gestation); at this stage, their commitment to a cardiac fate remains plastic (Fig. 1E) (Buckingham et al. 2005). At E8, or 3 weeks in human gestation, the cardiac crescent fuses at the midline and gives rise to the FHF-derived linear heart tube (Fig. 1E), which subsequently commences beating and undergoes rightward looping and rapid growth (mouse E8.5, 4 weeks in human development) (Fig. 1F) (Zaffran et al. 2004). As development proceeds, the linear heart tube expands, essentially by two mechanisms: (i) cell proliferation, and (ii) recruitment of additional cells. These additional cells, which are added to the arterial and venous poles of the linear heart tube, originate from the pharyngeal mesoderm located caudal to the pharynx, and represent the SHF (Mjaatvedt et al. 2001; Waldo et al. 2001; Buckingham et al. 2005; Kelly 2012; Moorman et al. 2013). SHF progenitors mainly contribute to the OFT, the right ventricle, and a large portion of the inflow region (atria), whereas the left ventricle mainly derives from the FHF (Fig. 1F). The septated four-chambered fetal heart is subsequently generated involving intricate interactions of cardiomyocytes with epicardial and endocardial cells as well as CCNCs. At day E10.5 in mice (day 32 in human) the developing heart shows well-defined chambers (Fig. 1G), which are fully septated and connected to the pulmo-

Figure 1. (Continued) At E8.0, the cardiac crescent forms the beating, linear heart tube. SHF progenitors will gradually migrate into the linear heart tube and differentiate then. $(F)$ At E8.5, the linear heart tube undergoes rightward looping. $(G)$ At E10.5, cardiac neural crest and proepicardial cells contribute to the heart, which already shows a defined four-chamber morphology. $(H)$ At E14.5, the heart shows four fully septated chambers and a septated outflow tract connected to the pulmonary trunk and the dorsal aorta. AA, Aortic arch; ant, anterior; AO, dorsal aorta; CNCC, cardiac neural crest cells; do, dorsal; EPI, epicardium; FHF, first heart field; HF, headfolds; IVS, interventricular septum; L, left; LA, left atrium; LV, left ventricle; OFT, outflow tract; PE, proepicardium; PhA, pharyngeal arch; PLA, primitive left atrium; post, posterior; PRA, primitive right atrium; PS, primitive streak; PT, pulmonary trunk; R, right; RA, right atrium; RV, right ventricle; SHF, second heart field; SMCs, smooth muscle cells; ven, ventral. 
T. Brade et al.

nary trunk and aorta at E14.5 ( 7 weeks in human gestation) (Fig. $1 \mathrm{H})$.

\section{From Mesoderm Induction to Cardiogenic Mesoderm Progenitors}

Mesoderm induction, a quintessential prerequisite for heart development, is evolutionarily conserved and regulated by numerous signaling pathways. Key players are Nodal and bone morphogenetic protein (BMP) signals as well as Wnt and fibroblast growth factors (FGF) (Kimelman 2006; Noseda et al. 2011). Expression of the T-box transcription factor Brachyury/T (Bry), a direct target gene of $\mathrm{Wnt} / \beta$-catenin signaling, marks mesodermal cells ingressing through the PS (Showell et al. 2004). Commitment of nascent $\mathrm{Bry}^{+}$mesodermal progenitors toward a cardiogenic fate requires inhibition of canonical Wnt/ $\beta$-catenin signaling and activation of noncanonical Wnt signaling (Gessert and Kuhl 2010). Moreover, intricate interactions between the mesodermal germ layer and the endoderm are additionally necessary for the induction of a common primordial cardiovascular progenitor population from $\mathrm{Bry}^{+}$mesodermal precursors, which later give rise to both first and second heart field progenitors (Figs. 1 and 2) (Abu-Issa et al. 2004; Buckingham et al. 2005). Tracing cardiogenic fate back to $\mathrm{aBry}^{+}$population sparked the idea of a clonal model of heart lineage diversification analogous to hematopoiesis, in which a single hematopoietic stem cell can generate all blood-cell lineages (Weissman 2000). According to this hierarchy model, diverse muscle and nonmuscle lineages arise from a single-celllevel decision of multipotent, primordial cardiovascular stem cells, which in turn give rise to downstream intermediates representing tissue-restricted precursors of fully differentiated heart cells (Fig. 2). First, data supporting this hypothesis have been gained by lineage-tracing studies, and marker gene expression analysis in mice showing that the endocardial endothelium and the myocytic lineage develop from an intermediate mesodermal population that expresses vascular endothelial growth factor receptor 2 (VEGFR2, Flk-1, KDR) (Motoike et al. 2003; Ema et al. 2006). These initial findings were corroborated by additional in vivo and in vitro studies. During development as well as during in vitro differentiation of mouse and human embryonic stem cells, two distinct Bry ${ }^{+}$cell populations arise (Fig. 2). First, a Bry ${ }^{+} / \mathrm{Flk}_{-1}^{+}$ hemangioblast precursor population contributes cells to the hematopoietic system and the developing vasculature. During subsequent development, $\mathrm{Bry}^{+} / \mathrm{Flk}^{-1}{ }^{-}$mesodermal progenitors initiate a new wave of Flk-1 expression and constitute cardiovascular progenitors (Fig. 2) (Kouskoff et al. 2005; Kattman et al. 2006; Yang et al. 2008). Later, this primitive $\mathrm{Bry}^{+} / \mathrm{Flk} 1^{+}$ cardiogenic mesoderm population down-regulates Bry and activates, upon T-box transcription factor Eomesodermin action, expression of the mesoderm posterior 1 (Mesp1) gene (Fig. 2) (Bondue and Blanpain 2010; Costello et al. 2011). Mesp $1^{+}$mesodermal progenitors contribute to paraxial mesoderm and skeletal muscle of the head as well as cardiac muscle (Saga et al. 2000; Scott 2012). By turning on the core cardiogenic transcriptional network, Mesp1 has been shown to further restrict these primitive mesodermal precursors toward a cardiovascular and anterior mesodermal fate (Bondue et al. 2008; Martin-Puig et al. 2008; Bondue and Blanpain 2010).

\section{Differentiation of Early Cardiogenic Mesoderm Progenitors - Formation of the Cardiac Crescent and the Linear Heart Tube}

After ingression through the PS, cardiogenic progenitor cells migrate to an anterior lateral position caudal to the headfolds and form the so-called cardiac crescent. At this time in development, the first and second heart fields can be distinguished (Moorman et al. 2013). Although the FHF progenitors already differentiate at this stage, cells within the SHF remain in a proliferative, undifferentiated progenitor state until they enter the heart tube at a later time point (Kelly 2012). In fact, because of their position in the crescent (more anterior and lateral in respect to SHF progenitors) (Fig. 1E), FHF progenitor cells are exposed to cytokines of the BMP (Schultheiss et al. 1997) and FGF (Reifers et al. 2000) families as well as to inhibitors of the 


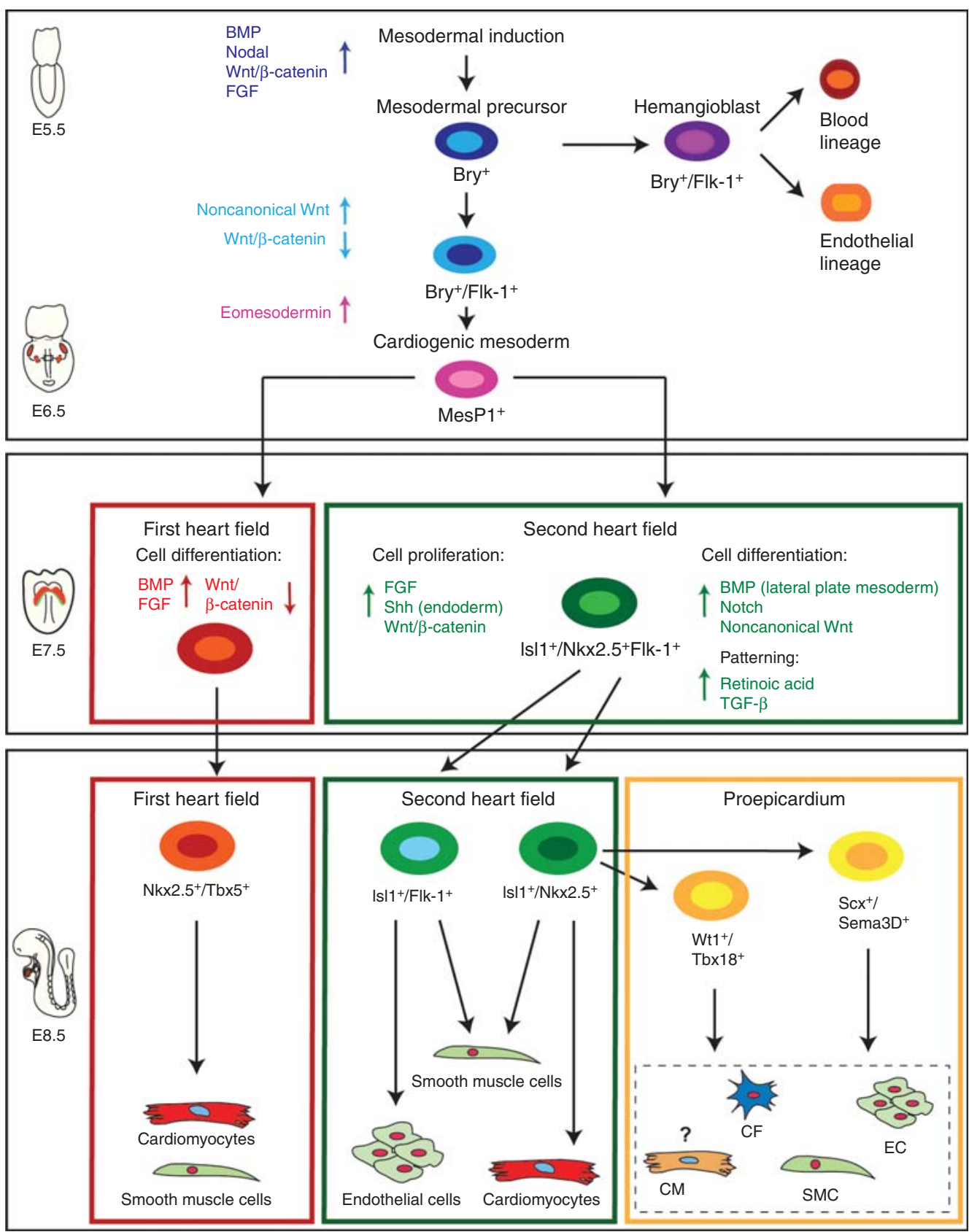

Figure 2. Cellular hierarchy of cardiac progenitor cells and their lineage specification. Several signaling pathways (BMP, Nodal, Wnt/ $\beta$-catenin, FGF) interact to induce mesoderm; Brachyury (Bry) positive mesodermal precursors first differentiate through $\mathrm{Bry}^{+} / \mathrm{Flk}_{-} 1^{+}$hemangioblasts toward endothelial and blood-cell lineages (around E5.5 during mouse development). Slightly later during development after down-regulation of Wnt $/ \beta$ catenin signaling and induction of noncannonical Wnt signals a second wave of $\mathrm{Bry}^{+} / \mathrm{Flk}-1^{+}$mesodermal progenitors appears. Eomesodermin signaling drives cardiogenic mesoderm specification from these primitive mesodermal precursors. Cardiogenic mesoderm is marked by the expression of mesoderm posterior 1 (Mesp1) (around E6.5 in mouse embryogenesis). (Legend continues on following page.) 
T. Brade et al.

Wnt pathway (Marvin et al. 2001; Schneider and Mercola 2001; Tzahor and Lassar 2001; Noseda et al. 2011), resulting in the onset of cardiac differentiation marked by the expression of key regulators of the lineage, namely, Nkx2.5 (Lints et al. 1993), Gata-4 (Arceci et al. 1993; Kelley et al. 1993; Heikinheimo et al. 1994; Zeisberg et al. 2005), and Tbx5 (Harvey 2002). Myocytic lineage commitment is associated with expression of contractile proteins including myosin light chain-2a (MLC2a) (Kubalak et al. 1994) and sarcomeric myosin heavy chain (MHC) first in the cardiac crescent and then throughout the linear heart tube.

Although no genes uniquely expressed in early FHF progenitors have been identified yet, SHF precursors are marked by the LIM-homeodomain transcription factor Isl-1. Although several studies suggest Isl-1 to be a very early pancardiac marker, after formation of the linear heart tube, Isl-1 clearly demarcates the SHF and its expression is absent in differentiated FHF derivatives (Prall et al. 2007; Kelly 2012). Isl-1 expression is dependent on canonical Wnt signaling (Tzahor 2007; Cohen et al. 2008), and its function is required for survival, proliferation, and migration of into the primitive heart tube of the SHF progenitors. Isl-1 expression is extinguished as progenitor cells reach the developing heart and differentiate (Cai et al. 2003). Several studies have shown that the molecular signature Isl- $1^{+} / \mathrm{Nkx} 2.5^{+} / \mathrm{Flk}-1^{+}$marks a specific pool of primitive SHF progenitors that are multipotent and give rise, by further lineage restriction, to downstream tissue-specific intermediates generating both myocytic and vascular cells (Fig. 2) (Kattman et al. 2006; Moretti et al. 2006; Wu et al. 2006; Bu et al. 2009). In particular, Isl- $1^{+} / \mathrm{Nkx} 2.5^{+}$descendants (that have lost Flk-1 expression) are committed to form cardiomyocytes and smooth muscle cells (SMCs), extensively contributing to the proepicardium/ epicardium (Cai et al. 2008; Zhou et al. 2008a,b), whereas the Isl- $1^{+} / \mathrm{Flk}^{+}{ }^{+}$subset (in which Nkx2.5 expression has ceased) differentiates to form endothelial cells and SMCs (Fig. 2) (Moretti et al. 2006). The fate of SHF progenitors is controlled by many different signaling pathways. Among them, FGF signaling within the SHF promotes progenitor cell proliferation; Shh-mediated signals from the endoderm and canonical Wnt signaling from the midline (neural tube) are important for the maintenance of a proliferative state and inhibition of differentiation (Kelly 2012). On the contrary, BMPs secreted from lateral plate mesoderm as well as Notch and noncanonical Wnt signals promote cardiac differentiation of SHF progenitors (Vincent and Buckingham 2010). Furthermore, mechanisms of epigenetic control (e.g., miRNA, lncRNA) are also important regulators of the progression of progenitors to terminally differentiated cardiac muscle and nonmuscle lineages (Liu and Olson 2010).

Taking together two decades' worth of research data, we can now construct a core transcriptional and signaling network regulating early cardiac development. This highly com-

Figure 2. (Continued) Early mesoderm-derived cardiac precursors undergo further lineage restriction and differentiate into progenitor pools that populate the FHF and SHF, respectively. At this stage (E7.5 mouse development) FHF progenitors start to differentiate upon BMP and FGF action toward cardiomyocytes and smooth muscle cells, whereas Wnt/ $\beta$-catenin, FGF, and endodermal Shh signaling keeps SHF progenitors in a proliferative state. These SHF progenitors are defined by the molecular signature Isl- $1^{+} / \mathrm{Nkx} 2.5^{+} / \mathrm{Flk}-1^{+}$. SHF progenitors are now gradually added to the looping heart tube and get further restricted in their differentiation potential (E8.5). Two subpopulations of SHF progenitors can be distinguished. One population marked by the expression of Isl-1 and Flk-1 differentiates into endothelial cells and smooth muscle cells, whereas a second pool of Isl- $1^{+} / \mathrm{Nkx} 2.5^{+}$SHF precursors provides smooth muscle cells and cardiomyocytes as well as contributing to the proepicardial lineages ( $\mathrm{Wt}^{+} / \mathrm{Tbx} 18^{+}$and $\mathrm{Scx}^{+} / \mathrm{Sema} \mathrm{D}^{+}$populations), which later form cardiac fibroblasts (CF), smooth muscle cells (SMCs), endothelial cells (EC), and cardiomyocytes (CM), with the latter contribution being still unclear. These distinct SHF progenitor populations differentiate upon BMP signals from the lateral plate mesoderm as well as Notch and noncanonical Wnt signals. SHF patterning is governed by RA and TGF- $\beta$ signals. 
plex network of spatiotemporal interactions of growth factors and transcriptional regulators (e.g., BMP, Wnt, FGF, Nkx2.5, and Gata4) governs both FHF and SHF development (Kelly 2012; Harvey 2013; Moorman et al. 2013). Importantly, our current knowledge supports a new paradigm for cardiovascular development involving the divergence of myocardial, smooth muscle and endothelial cell lineages from a common precursor.

\section{THE PROEPICARDIUM}

The early embryonic heart tube developing from the FHF and SHF progenitors consists only of two cell layers, the endocardium and the myocardium. The epicardium, the outermost layer of the heart, and the epicardium-derived cells (EPDCs), which are found in the mature heart, such as cardiac fibroblasts and cells of the coronary vasculature, are not present at the tubular heart stage. These cell lineages arise later (between E9.5 and E11.5 in mouse development) (Fig. 1) and are derived from a cluster of cells, which is known as the proepicardium (PE).

\section{Induction of the Proepicardium and Epicardium Formation}

The transitory structure of the PE arises from the coelomic mesenchyme of the septum transversum in close proximity to the venous pole of the linear heart tube at E 8.5 (d21 in human gestation) (Manner et al. 2001). PE induction, growth, and maintenance depends, among others, on opposing interaction between FGF signaling, which induces a proepicardial fate in the posterior splanchnic mesoderm, and BMP signaling, driving myocardial differentiation of this cell population (Kruithof et al. 2006; van Wijk et al. 2009; Torlopp et al. 2010; Schlueter and Brand 2012). PE progenitors are marked by the expression of Tbx18 and Wt1 (Kraus et al. 2001; Cai et al. 2008; Zhou et al. 2008b) as well as by FHF and SHF markers Nkx2-5 and Isl-1 (Zhou et al. 2008b). One important question concerns heterogeneity of PE progenitors, which could represent early-segregated progenitor pools. Earlier studies in chicken embryos showed at least two morphologically different proepicardial cell populations: (1) an external mesothelial epithelium, and (2) an internal extracellular matrix (ECM)-rich mesenchymal core (Nahirney et al. 2003). Although no morphological differences have been described in mammalian PE cells, a very recent lineage-tracing study in mouse analyzing semaphorin3 $\mathrm{D}^{+}$ $\left(\mathrm{Sema}^{+}\right)$and scleraxis ${ }^{+}\left(\mathrm{Scx}^{+}\right)$PE progenitors revealed that these cells show a distinct differentiation potential from earlier described $\mathrm{Tbx}_{18}{ }^{+}$and $\mathrm{Wt}^{+}$proepicardial cells, confirming the data on PE heterogeneity evident from studying the avian system (Katz et al. 2012). In mammals, freely floating PE cell vesicles are released from the PE anlage, which flatten and spread out on contact to the naked myocardium, thereby forming the epicardium between E9.5 and E11.5 in mouse development (Fig. 3A). Genetic evidence from mouse embryos suggests a crucial role for cell adhesion molecules (vascular cell adhesion molecule [VCAM] and b4-a1-integrin) in this process (Kwee et al. 1995; Yang et al. 1995).

The Epicardium- and Epicardial-Derived Cells Govern Chamber Maturation and Coronary Vessel Formation

After the epicardium has been formed, a whole array of interacting signaling pathways drive (1) epicardial epithelial to mesenchymal transition (EMT) and formation of EPDCs, (2) differentiation of EPDCs into different cell lineages, (3) induction of compact zone growth, as well as (4) establishment of coronary vessel formation (Fig. 3B,C). Once the epithelial cell sheet of the epicardium is formed, directed proliferation parallel or perpendicular to the cellular basement membrane leads to the expansion of the epicardium in the former case or the induction of EMT and subsequent migration and differentiation of EPDCs in the latter. Wt1 signaling is a key factor for normal progression of epicardial EMT as well as EPDC differentiation and myocardial growth (Martinez-Estrada et al. 2010; von Gise et al. 2011; Lim and Thiery 2012).

EPDC differentiation and myocardial compact zone growth depend on a network of recipro- 
T. Brade et al.

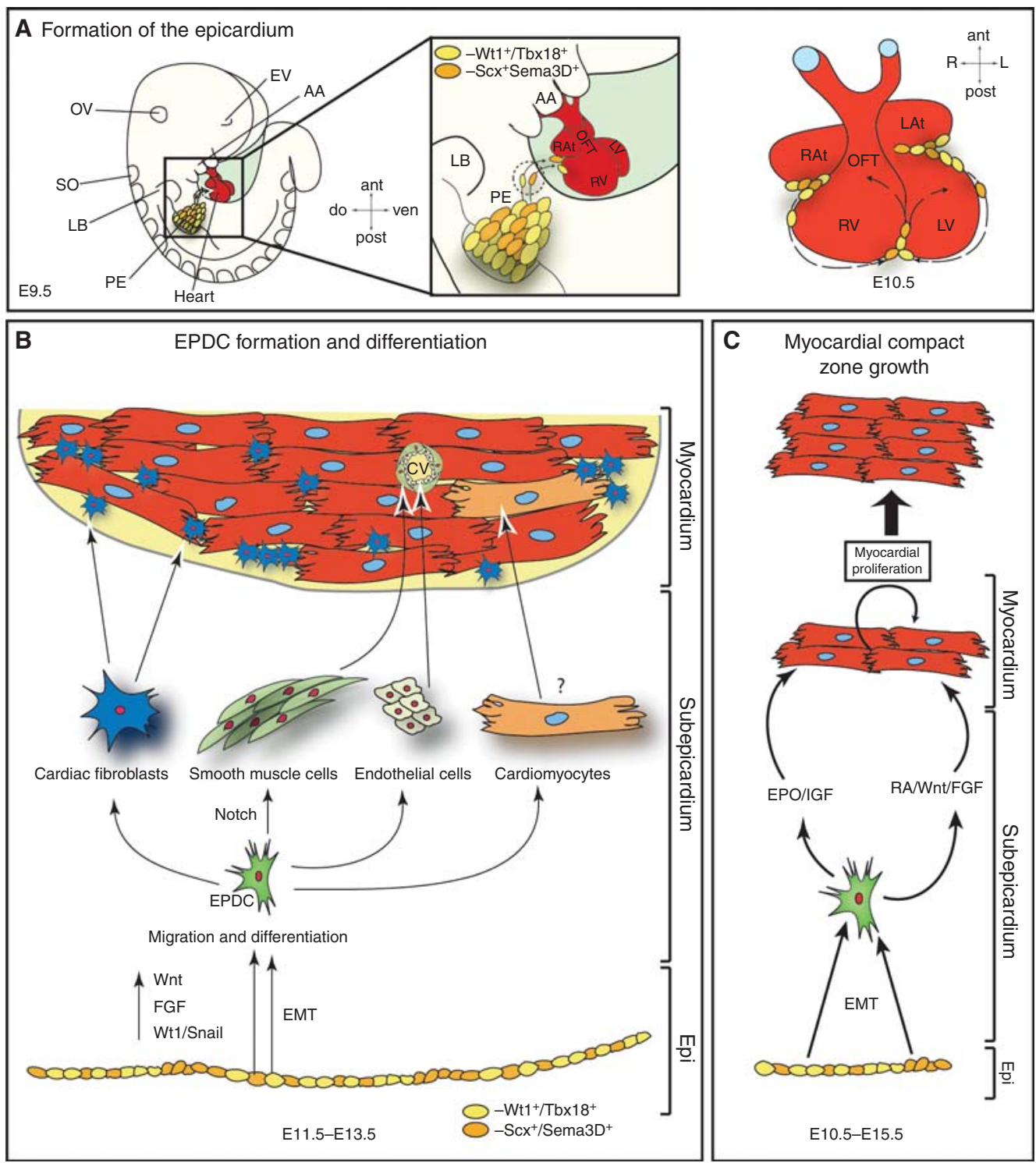

Figure 3. Origin and fates of the proepicardium. (A) Formation of the epicardium. Starting around E9.5 of mouse development, freely floating proepicardial cell vesicles attach to the naked myocardium, starting in the atrioventricular canal region. The whole heart will be covered by an epicardial epithelial sheet by E11.5. (B) Formation of epicardium-derived cells (EPDCs). At E11.5-13.5, epicardial cells undergo an epithelial-mesenchymal transition (EMT) (mediated by Wnt, FGF, and Wt1/Snail signals) and EPDCs emerge in the subepicardial space. EPDCs then differentiate toward various cell types, as indicated, and contribute to the coronary vasculature (cv) and cardiac fibroblast. EPDC differentiation toward the myocytic lineage is still under thorough investigation. $(C)$ Epicardium/EPDCs are secreting important factors that induce myocardial proliferation and thereby myocardial compact zone growth. AA, Aortic arches; ant, anterior; cv, coronary vessels; do, dorsal; EMT, epithelial to mesenchymal transition; EPDC, epicardial-derived cells; Epi, epicardium; EPO, erythropoietin; EV, eye vesicle; IGF, insulin growth factor; L, left; LAt, left atrium; LB, limb bud; LV, left ventricle; OFT, outflow tract; OV, otic vesicle; PE, proepicardium; post, posterior; R, right; RA, retinoic acid; RAt, right atrium; RV, right ventricle; $\mathrm{SO}$, somites; ven. ventral. 
cal epicardium-myocardium signaling of largely unknown nature (Fig. 3C) (Perez-Pomares and de la Pompa 2011). There is still extensive discussion about the potential contribution of EPDCs to different cell lineages (Gittenbergerde Groot et al. 2012). Although it is consensus in the field that EPDCs can differentiate toward a cardiac fibroblast and vascular smooth muscle cell fate, formation of coronary endothelial cells and cardiomyocytes by EPDCs is less clear (Fig. 3B). Tabin and colleagues have shown for the first time that the mammalian epicardium consists of distinct cell populations that can give rise to endothelial cells (Katz et al. 2012). The vast majority of cardiomyocytes, on the other hand, seem to be derived from other sources (Gittenberger-de Groot et al. 2012). Signaling molecules with a prominent role in EPDC differentiation and compact zone growth are FGFs, Notch and retinoic acid (Sucov et al. 2009). Two different RA signaling networks have been proposed. One study showed that an RA stimulus is necessary to induce hepatic erythropoietin (Epo) production. Epo in turn induces epicardial IGF-2 secretion, which then acts as a proliferative factor on compact zone myocytes (Brade et al. 2011; Li et al. 2011). Other studies placed Wt1 upstream of epicardial Raldh2 (a key molecule in RA metabolism) expression (Guadix et al. 2011). RA signaling in turn has been described earlier to spearhead a signaling network that includes cross talk with Wnt and FGF signaling molecules (Fig. 3C) (Merki et al. 2005; Lavine et al. 2006; Zamora et al. 2007).

Formation of the coronary vessels is tightly linked to compact zone growth and relies on overlapping signaling molecules (Olivey and Svensson 2010; Perez-Pomares and de la Pompa 2011). Mesenchymal cells in the subepicardial space and in the myocardial wall (most of them if not all are EPDCs) will coalesce and differentiate, thereby forming the primitive coronary plexus around E11.5 during mouse development (Reese et al. 2002). Primary coronary vessels spread over the entire ventricle until E13.5; afterward, intricate remodeling and arterial and venous differentiation takes place. Important signaling molecules driving these processes include the aforementioned FGFs and
Embryonic Heart Progenitors and Cardiogenesis

RA signaling as well as ligands belonging to the Hedgehog and VEGF families and the TGF- $\beta$ superfamily (Lavine and Ornitz 2008; Olivey and Svensson 2010; Perez-Pomares and de la Pompa 2011). Moreover, epicardial Notch signaling is required for vSMC differentiation, whereas it is dispensable for EMT or migration and myocardial growth (del Monte et al. 2011; Grieskamp et al. 2011).

\section{CARDIAC NEURAL CREST PROGENITORS}

The third distinct embryonic heart progenitor population that is involved in cardiogenesis consists of the CNCCs. CNCCs comprise a noncardiac cell type important for proper patterning of the aortic arteries, for OFT development and septation, and normal myocardial function. Although CNCCs are differentiating into ectomesenchyme and aortic smooth muscle cells as well as forming the aorticopulmonary septum, which divides the arterial outlet of the heart, it seems that the main role of CNCCs in the abovementioned developmental processes is to provide signals rather than actively contribute differentiated cells to the specific cardiac structures. That said, there is a direct pivotal cellular contribution of the crest to the heart valves and they provide all parasympathetic innervation of the heart (Fig. 1C).

Signaling Pathways Governing Cardiac Neural Crest Cell Induction and Migration

CNCCs are a subpopulation of the cranial neural crest cells and arise from the dorsal neural tube between the mid-otic placode and the posterior border of somite 3 (Fig. 4A) (Keyte and Hutson 2012). The crest cells delaminate from the neural tube and migrate on preset routes toward the heart, reaching the pharyngeal arches 3 , 4, and 6 (Fig. 4B). Signals important for the induction of the CNC progenitors belong to the BMP/TGF- $\beta$ superfamily of growth factors as well as to the FGF, Wnt/ $\beta$-catenin, and retinoic acid signaling pathways. These different families of secreted molecules control key aspects of neural crest biology, starting from the establishment of the neural plate border up to the cytosekeletal 
T. Brade et al.
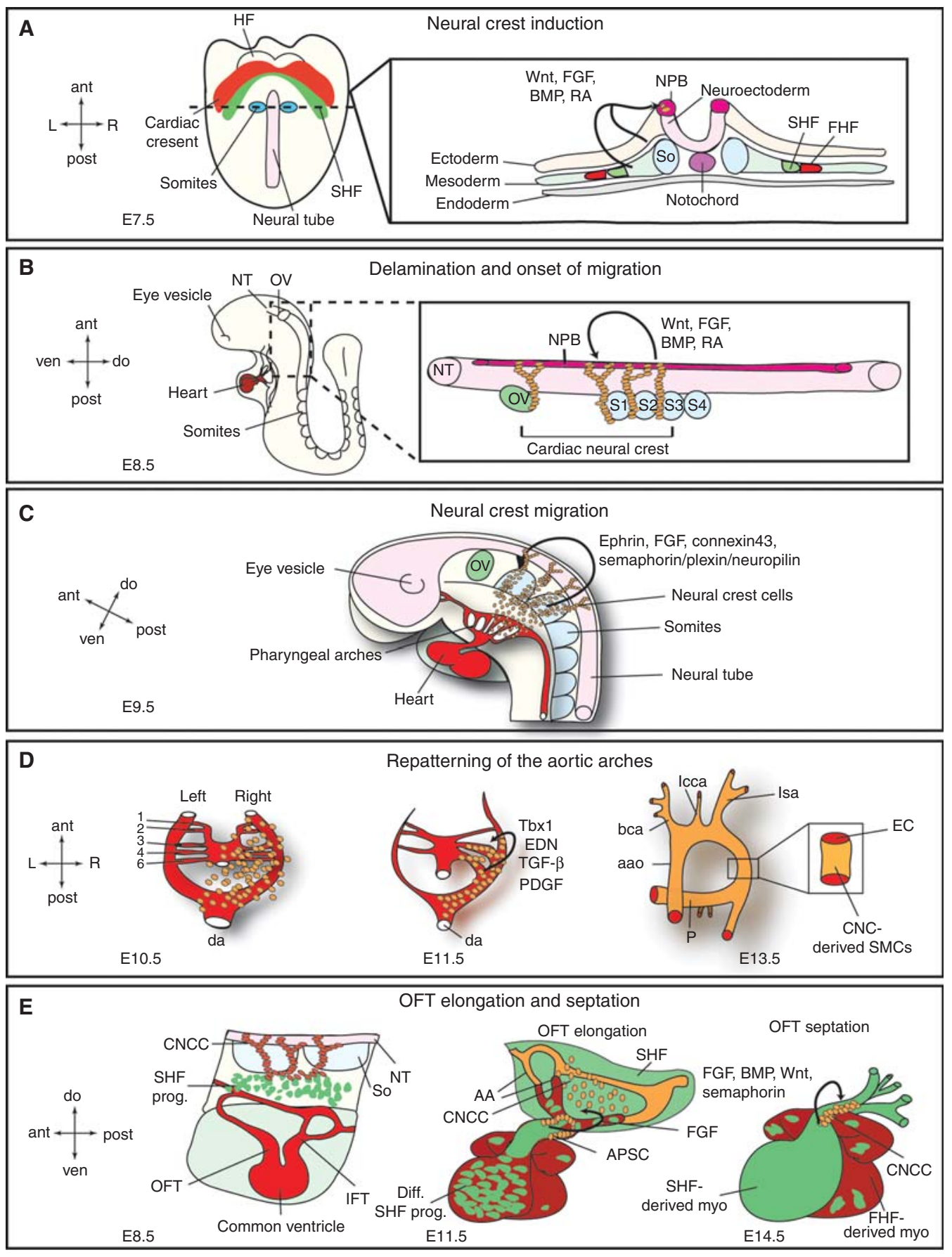

Figure 4. Cardiac neural crest. (A) Neural crest induction. Illustrated is a ventral view of an E7.5 embryo and a transverse section through the first somite pair. The section detail shows the different germ layers and factors originating in the ectoderm and mesoderm that are required for neural crest cell induction in the neural plate border (NPB). Ant, anterior; post, posterior; R, right; L, left; HF, headfolds; FHF, first heart field; SHF, second heart field; So, somite. $(B)$ Delamination and onset of migration of cardiac neural crest cells. (Legend continues on facing page.) 
rearrangements required for delamination of neural crest cells from the neural tube and onset of migration (Fig. 4A,B) (Scholl and Kirby 2009).

After induction and delamination the crest cells migrate along specific routes guided by chemical attractant and repellent cues toward the heart (Fig. 4C). Important molecules for this process belong to the ephrin family of ligands and receptors that ensure specific migration patterns alongside FGF signaling molecules, semaphorins and connexin 43 (Kuriyama and Mayor 2008). Semaphorin/plexin/neuropilin signaling is suggested as a targeting cue to the OFT cushions and Cx43 seems to facilitate proper migration and survival. Intricate interactions along their path between the pharyngeal ectoderm and endoderm and continuous proliferation ensure that the CNC progenitors reach their target areas in the heart in sufficient numbers (Xu et al. 2006; Keyte and Hutson 2012).

\section{Signaling Pathways Instructing CNC Cells during Aortic Arch Artery Patterning and OFT Septation}

Once the crest cells reached the pharyngeal arches, endothelin, TGF- $\beta$, and PDGF signaling pathways are crucial for the CNCCs to exert their role in patterning the aortic arch arteries (Fig. 4D). Endothelin (END) signals are important for the maintenance of the instructive cues of CNCCs during this process and, although downstream effectors are not well understood yet, Hand2 seems to process endothelin signals in the aortic arches. TGF- $\beta$ signals are thought to provide important antiapoptotic effects, and PDGF signals ensure proliferation and maintenance (Hutson and Kirby 2007). T-box transcription factors (namely, Tbx1) also play a key role in neural crest biology. Although not expressed in CNCCs themselves, Tbxl regulates the expression of the guidance molecule Slit in the pharyngeal endoderm. Loss of Slit function has been shown to prevent CNCC migration into aortic arch 4 and thereby leading to interrupted aortic arch. Besides that, Tbxl also interacts with FGF-8, whose levels need to be regulated in a very confined manner for CNCC survival as well as for timing and targeting of the migrating progenitors to the pharynx (Abu-Issa et al. 2002; Sato et al. 2011).

Additional to their role in aortic arch patterning CNCCs exert another important function in OFT development and septation (Fig. $4 \mathrm{E}$ ). One of the earliest detectable defects after CNCC ablation is defective looping because of a shortened OFT. This phenotype is caused by altered SHF progenitor addition to the developing OFT. In CNCC ablated chick embryos altered FGF-8 levels keep the SHF progenitors in a proliferative state, precluding proper migration and

Figure 4. (Continued) At E8.5, cardiac neural crest cells delaminate from the NPB between the mid-otic vesicle (ov) and the posterior border of somite 3 (S3) and start on their migratory path toward the heart. These processes are mediated by Wnt, FGF, BMP, and RA signals. Please see text for more details. ant, anterior; post, posterior; ven, ventral; do, dorsal; S1,2,3,4, somite 1,2,3,4. (C) Neural crest migration. By E9.5, the CNCCs reach the aortic arches and are proceeding toward the OFT. Signals targeting the CNCCs to the aortic arches are indicated. ov, otic vesicle. $(D)$ The CNCCs are vital for the repatterning of the aortic arches. There are initially six symmetrical arteries attached to the parallel dorsal aorta (da). Sequentially these arteries are remodeled and give rise to a separate ascending aorta (aao) and pulmonary trunk (P) with two pulmonary arteries attached. Additionally, the cardiac neural crest cells are differentiating into aortic smooth muscle cells and envelope the nascent endothelial cells forming the aortic arches. Required factors for both processes are indicated (END, endothelin); see text for details. bca, Brachiochepalic artery; lcca, left common carotid artery; lsa, left subclavian artery. (E) Interaction of CNCCs and SHF progenitors leads to outflow tract (OFT) elongation and septation. At E11.5, cardiac neural crest cells condense and form the U-shaped aorticopulmonary septation complex (APSC); see text for details. CNCC, Cardiac neural crest cells; SHF prog., second heart field progenitors; NT, neural tube; So, somites; IFT, inflow tract; diff. SHF prog., differentiated second heart field progenitors; AA, aortic arches; FHF derived myo., first heart field-derived myocardium; SHF derived myo, second heart fieldderived myocardium. 
T. Brade et al.

eventually initiation of myocardial differentiation (Waldo et al. 2005; Ilagan et al. 2006; Scholl and Kirby 2009). Furthermore, upon CNCC ablation myocardial function is deranged, which is indicated by disrupted $\mathrm{Ca}^{2+}$ handling and depressed ejection fraction (Hutson et al. 2006). Further down the developmental road, CNCCs govern OFT septation. In the avian model system, the CNCCs reach the OFT cushions subendocardially and submyocardially where they form together with mesenchymal cells the socalled aorticopulmonary septation complex, which will initiate the division of the systemic and pulmonary blood flow (Keyte and Hutson 2012). Multiple signaling pathways are implicated to instruct CNCCs during this process, the major players being BMP, Wnt, and semaphorin signaling (Fig. 4E). The cellular contribution of the CNCCs to the cardiac conduction system and the cardiac valves remains an ongoing debate but development of both structures is obscured upon loss of neural crest function, indicating that at least signals from CNCCs are required for their normal development (Hutson and Kirby 2007).

\section{EMBRYONIC CARDIAC PROGENITORS AND CONGENITAL HEART DISEASE}

Congenital heart disease (CHD) is one of the most prevalent forms of human birth defects, affecting $0.4 \%-5 \%$ of live births, depending on which level of severity of CHD is included in the statistics. Moreover, around 30\% of prenatal loss is owing to heart malformations (Hoffman 1995; Bruneau 2008). CHD most commonly arises from defective cardiac morphogenesis. In the last few decades, with our growing knowledge of normal cardiac development and of cardiac precursor origin and regulation, the role of the different embryonic cardiac progenitor populations (cardiac mesoderm progenitors, epicardial progenitors, and CNCCs) in the etiology of CHD has begun to gain increasing interest. Although disruption of embryonic cardiac progenitor biology (specification, proliferation, migration, lineage-specific differentiation) has not yet been assigned to be causative for any human $\mathrm{CHD}$, identification of transcriptional programs that are impaired in CHD patients and control key aspects of cardiac progenitor lineage diversification and fate strongly suggests compromised cardiac progenitor biology at the root of at least some human CHDs. Mutations in Nkx2.5 (e.g., atrial septal defects [ASD] and tetralogy of Fallot), Tbx5 (e.g., Holt-Oram syndrome, ASD, and ventricular septal defects [VSD]), and GATA-4 (e.g., ASD and VSD) point to cardiogenic mesoderm progenitor involvement, whereas mutations in the Tbxl gene (DiGeorge syndrome, 22q11 deletions) implicates CNCCs. The involvement of epicardial progenitors in CHD is not as straightforward, but a role in hypoplastic left heart syndrome has been suggested along with contributions to the left ventricular noncompaction phenotype and valve malformations (Bruneau 2008; Musunuru et al. 2010; Gittenberger-de Groot et al. 2012; Keyte and Hutson 2012).

The possibility of derailed embryonic cardiac progenitors contributing to the developing heart as a causative factor for human CHD enables intriguing explanations for some unresolved questions in CHD etiology. It is, for example, unclear why most CHDs are polygenic and have variable penetrance and disease severity even within one family (Fahed et al. 2013). Given the complex networks of cytokines, transcription factors as well as physical stimuli (e.g., cell-cell interactions, hemodynamic flow, cell migration) that are regulating cardiac progenitor development, it becomes feasible that a plethora of variables dictates the phenotypic characteristics of a certain CHD, which undoubtedly can vary even between siblings. Another puzzling question is how the same morphological phenotype is caused by seemingly unrelated genetic causes (Lage et al. 2012). This could be explained if we consider progenitor development gone awry as a basis for the cardiac malformation at hand.

\section{CARDIAC STEM AND PROGENITOR CELLS IN REGENERATIVE MEDICINE}

Ischemic heart disease and heart failure are the leading causes of death in the western world. Even if patients survive an ischemic event such 
as acute myocardial infarction (MI) their prognosis can be very poor. Diminished cardiac function owing to a massive loss of cardiomyocytes induces hypertrophic remodeling and eventually heart failure. Novel therapeutic avenues aiming at disrupting this vicious circle by renewal of lost cardiac muscle are greatly needed to improve our means to manage ischemic heart disease. Unfortunately, the regenerative capacity of the heart is extremely limited. Until recently, it was believed that the mammalian heart cannot regenerate at all owing to the inability of terminally differentiated cardiomyocytes to reenter the cell cycle and proliferate. Studies of the last few years have now provided evidence for cardiomyocyte turnover in the adult human heart. Although this process occurs at a low rate during normal homeostasis and aging of the heart, it seems to be elevated after injury (Bergmann et al. 2009; Parmacek and Epstein 2009; Kajstura et al. 2010; Senyo et al. 2013). It has been shown that mice can regenerate lost heart muscle within their first week of life, similarly to adult zebrafish, and that most of the new cardiomyocytes are mainly derived by cell division from preexisting cardiomyocytes (Jopling et al. 2010; Kikuchi et al. 2010; Porrello et al. 2011). Recently, a role of the epicardium and EPDCs in cardiac regeneration has been suggested. The epicardium seems to contribute mainly paracrine factors for myocardial proliferation and neovascularization as well as nonmyocytic lineages, therefore recapitulating embryonic development (Perez-Pomares and de la Pompa 2011; Kikuchi and Poss 2012).

Alternative options for improving cardiac function after MI arise from the purification of cardiac progenitors or cardiomyocytes differentiated from human embryonic or induced pluripotent stem cells (Burridge et al. 2012; Aguirre et al. 2013; Chien and Mummery 2013; Mummery 2013) and from direct in vivo reprogramming approaches. In recent years, a plethora of differentiation protocols driving hPSCs toward a cardiogenic fate have been established (Burridge et al. 2012; Mummery et al. 2012). However, clinical applications of hPSC-derived cells have so far been hampered by safety issues and low engraftment after injection in the injured
Embryonic Heart Progenitors and Cardiogenesis

heart (Aguirre et al. 2013). An exciting hope in the field of cardiac repair has come from the recent success in direct in vivo reprogramming of cardiac fibroblasts into cardiomyocytes using overexpression of Tbx5, Mef2c, and Gata4 in combination with Hand 2 or only using miRNAs (miRs-1/133/208/499) (Song et al. 2010; Jayawardena et al. 2012; Qian et al. 2012). These studies have shown improvements of cardiac function after direct reprogramming in experimental rodent models of MI, suggesting the potential of this new technology as a viable strategy for cardiac regeneration.

Although a lot of problems still need to be tackled, activation of endogenous regenerative processes, along with stem cell-based technologies, is holding great promise for possible future clinical applications. In the past 20 years we improved the path to be traveled to reach this goal and further efforts of many scientists and clinicians around the world will provide a silver lining in the battle against the world's biggest life threat (see also Chien and Mummery 2013 and Mummery 2013 for more details).

\section{CONCLUDING REMARKS}

The different embryonic heart progenitor lineages all rely on a great variety of spatiotemporal signals that tightly regulate their terminal differentiation. But it is noteworthy that recurring genetic regulatory networks are now emerging. For induction/specification of progenitor populations EMT is indispensable. Here factors of the TGF- $\beta$ superfamily play a vital role. Once the multipotent progenitor cell state is reached, this population needs to proliferate and maintain an undifferentiated state to ensure enough terminally differentiated cells for the developing organ. Here canonical Wnt and FGF signaling factor as well as RA are used, among others. Differentiation toward specialized cell types is then achieved by BMP growth factors (myocardium) and Notch signaling (vascular cell types). These genetic loops are fine-tuned by transcription factors and noncoding RNAs, gradually restricting the differentiation potential of the specific lineage. To transfer our knowledge of cardiac development to the bedside, the field faces new chal- 
T. Brade et al.

lenges within the coming years. One task would be to decipher definitive molecular signatures that mark cardiac precursors in a spatiotemporally defined manner and enables researchers to specifically isolate and analyze distinct progenitor populations in greater detail. Although we have elucidated some marker genes for embryonic heart progenitors, the segregation of distinct progenitor populations with defined differentiation potential remains incomplete, and known marker genes are so far not exclusive for a given population. Additionally, molecular signatures comprised by cell surface molecules rather than transcription factors would greatly help to better analyze precursor biology in vitro, which would give us tools at hand to further delineate factors needed for survival and differentiation. Great progress has been made in our understanding of the embryonic development of the heart. But so far we have only understood the broad concept of induction, proliferation/ maintenance, and differentiation. It will require further efforts in filling the gaps to fully comprehend complex etiologies of human CHDs and to modulate embryonic developmental processes in vitro and in vivo to restore myocardial function in ischemic heart diseases.

\section{ACKNOWLEDGMENTS}

K.-L.L. acknowledges and thanks the German Research Foundation and the European Research Council for their ongoing support of research in the Laugwitz laboratory. A.M. is supported by grants of the German Research Foundation and the German Ministry for Education and Research. K.-L.L. and A.M. also acknowledge the Munich Heart Alliance, a member of the German Centre for Cardiovascular Research.

\section{REFERENCES}

${ }^{*}$ Reference is also in this collection.

Abu-Issa R, Smyth G, Smoak I, Yamamura K, Meyers EN 2002. Fgf8 is required for pharyngeal arch and cardiovascular development in the mouse. Development 129: 4613-4625.

Abu-Issa R, Waldo K, Kirby ML. 2004. Heart fields: One, two or more? Dev Biol 272: 281-285.
Aguirre A, Sancho-Martinez I, Izpisua Belmonte JC. 2013 Reprogramming toward heart regeneration: Stem cells and beyond. Cell Stem Cell 12: 275-284.

Arceci RJ, King AA, Simon MC, Orkin SH, Wilson DB. 1993. Mouse GATA-4: A retinoic acid-inducible GATA-binding transcription factor expressed in endodermally derived tissues and heart. Mol Cell Biol 13: 2235-2246.

Bergmann O, Bhardwaj RD, Bernard S, Zdunek S, BarnabeHeider F, Walsh S, Zupicich J, Alkass K, Buchholz BA, Druid H, et al. 2009. Evidence for cardiomyocyte renewal in humans. Science 324: 98-102.

Bondue A, Blanpain C. 2010. Mesp1: A key regulator of cardiovascular lineage commitment. Circ Res 107: 14141427.

Bondue A, Lapouge G, Paulissen C, Semeraro C, Iacovino M, Kyba M, Blanpain C. 2008. Mespl acts as a master regulator of multipotent cardiovascular progenitor specification. Cell Stem Cell 3: 69-84.

Brade T, Kumar S, Cunningham TJ, Chatzi C, Zhao X, Cavallero S, Li P, Sucov HM, Ruiz-Lozano P, Duester G. 2011. Retinoic acid stimulates myocardial expansion by induction of hepatic erythropoietin which activates epicardial Igf2. Development 138: 139-148.

Bruneau BG. 2008. The developmental genetics of congenital heart disease. Nature 451: 943-948.

Bu L, Jiang X, Martin-Puig S, Caron L, Zhu S, Shao Y, Roberts DJ, Huang PL, Domian IJ, Chien KR. 2009. Human ISL1 heart progenitors generate diverse multipotent cardiovascular cell lineages. Nature 460: 113-117.

Buckingham M, Meilhac S, Zaffran S. 2005. Building the mammalian heart from two sources of myocardial cells. Nat Rev Genet 6: 826-835.

Burridge PW, Keller G, Gold JD, Wu JC. 2012. Production of de novo cardiomyocytes: Human pluripotent stem cell differentiation and direct reprogramming. Cell Stem Cell 10: $16-28$

Cai CL, Liang X, Shi Y, Chu PH, Pfaff SL, Chen J, Evans S. 2003. Isl1 identifies a cardiac progenitor population that proliferates prior to differentiation and contributes a majority of cells to the heart. Dev Cell 5: 877-889.

Cai CL, Martin JC, Sun Y, Cui L, Wang L, Ouyang K, Yang L, Bu L, Liang X, Zhang X, et al. 2008. A myocardial lineage derives from Tbx18 epicardial cells. Nature 454: 104108.

* Chien K. 2013. Pluripotent stem cell technology and regenerative cardiovascular medicine. Cold Spring Harb Perspect Med doi: 10.1101/cshperspect.a013870.

Cohen ED, Tian Y, Morrisey EE. 2008. Wnt signaling: An essential regulator of cardiovascular differentiation, morphogenesis and progenitor self-renewal. Development 135: 789-798.

Costello I, Pimeisl IM, Drager S, Bikoff EK, Robertson EJ, Arnold SJ. 2011. The T-box transcription factor Eomesodermin acts upstream of Mesp1 to specify cardiac mesoderm during mouse gastrulation. Nat Cell Biol 13: 1084-1091.

del Monte G, Casanova JC, Guadix JA, MacGrogan D, Burch JB, Perez-Pomares JM, de la Pompa JL. 2011. Differential Notch signaling in the epicardium is required for cardiac inflow development and coronary vessel morphogenesis. Circ Res 108: 824-836. 
Ema M, Takahashi S, Rossant J. 2006. Deletion of the selection cassette, but not cis-acting elements, in targeted Flk1-lacZ allele reveals Flk1 expression in multipotent mesodermal progenitors. Blood 107: 111-117.

Fahed AC, Gelb BD, Seidman JG, Seidman CE. 2013. Genetics of congenital heart disease: The glass half empty. Circ Res 112: 707-720.

Gessert S, Kuhl M. 2010. The multiple phases and faces of wnt signaling during cardiac differentiation and development. Circ Res 107: 186-199.

Gittenberger-de Groot AC, Winter EM, Bartelings MM, Goumans MJ, DeRuiter MC, Poelmann RE. 2012. The arterial and cardiac epicardium in development, disease and repair. Differentiation 84: 41-53.

Grieskamp T, Rudat C, Ludtke TH, Norden J, Kispert A. 2011. Notch signaling regulates smooth muscle differentiation of epicardium-derived cells. Circ Res 108: 813823.

Guadix JA, Ruiz-Villalba A, Lettice L, Velecela V, MunozChapuli R, Hastie ND, Perez-Pomares JM, Martinez-Estrada OM. 2011. Wt1 controls retinoic acid signalling in embryonic epicardium through transcriptional activation of Raldh2. Development 138: 1093-1097.

Harvey RP. 2002. Patterning the vertebrate heart. Nat Rev Genet 3: 544-556.

* Harvey R. 2013. Genetic networks. Cold Spring Harb Perspect Med doi: 10.1101/cshperspect.a013839.

Heikinheimo M, Scandrett JM, Wilson DB. 1994. Localization of transcription factor GATA-4 to regions of the mouse embryo involved in cardiac development. Dev Biol 164: 361-373.

Hoffman JI. 1995. Incidence of congenital heart disease. I: Postnatal incidence. Pediatr Cardiol 16: 103-113.

Hutson MR, Kirby ML. 2007. Model systems for the study of heart development and disease. Cardiac neural crest and conotruncal malformations. Semin Cell Dev Biol 18: $101-110$.

Hutson MR, Zhang P, Stadt HA, Sato AK, Li YX, Burch J, Creazzo TL, Kirby ML. 2006. Cardiac arterial pole alignment is sensitive to FGF8 signaling in the pharynx. Dev Biol 295: 486-497.

Ilagan R, Abu-Issa R, Brown D, Yang YP, Jiao K, Schwartz RJ, Klingensmith J, Meyers EN. 2006. Fgf8 is required for anterior heart field development. Development 133: 2435-2445.

Jayawardena TM, Egemnazarov B, Finch EA, Zhang L, Payne JA, Pandya K, Zhang Z, Rosenberg P, Mirotsou M, Dzau VJ. 2012. MicroRNA-mediated in vitro and in vivo direct reprogramming of cardiac fibroblasts to cardiomyocytes. Circ Res 110: 1465-1473.

Jopling C, Sleep E, Raya M, Marti M, Raya A, Izpisua Belmonte JC. 2010. Zebrafish heart regeneration occurs by cardiomyocyte dedifferentiation and proliferation. $\mathrm{Na}$ ture 464: 606-609.

Kajstura J, Gurusamy N, Ogorek B, Goichberg P, ClavoRondon C, Hosoda T, D’Amario D, Bardelli S, Beltrami AP, Cesselli D, et al. 2010. Myocyte turnover in the aging human heart. Circ Res 107: 1374-1386.

Kattman SJ, Huber TL, Keller GM. 2006. Multipotent flk- $1^{+}$ cardiovascular progenitor cells give rise to the cardio- myocyte, endothelial, and vascular smooth muscle lineages. Dev Cell 11: 723-732.

Katz TC, Singh MK, Degenhardt K, Rivera-Feliciano J, Johnson RL, Epstein JA, Tabin CJ. 2012. Distinct compartments of the proepicardial organ give rise to coronary vascular endothelial cells. Dev Cell 22: 639-650.

Kelley C, Blumberg H, Zon LI, Evans T. 1993. GATA-4 is a novel transcription factor expressed in endocardium of the developing heart. Development 118: 817-827.

Kelly RG. 2012. The second heart field. Curr Top Dev Biol 100: 33-65.

Keyte A, Hutson MR. 2012. The neural crest in cardiac congenital anomalies. Differentiation 84: 25-40.

Kikuchi K, Poss KD. 2012. Cardiac regenerative capacity and mechanisms. Annu Rev Cell Dev Biol 28: 719-741.

Kikuchi K, Holdway JE, Werdich AA, Anderson RM, Fang Y, Egnaczyk GF, Evans T, Macrae CA, Stainier DY, Poss KD. 2010. Primary contribution to zebrafish heart regeneration by gata $4^{+}$cardiomyocytes. Nature 464: 601-605.

Kimelman D. 2006. Mesoderm induction: From caps to chips. Nat Rev Genet 7: 360-372.

Kouskoff V, Lacaud G, Schwantz S, Fehling HJ, Keller G. 2005. Sequential development of hematopoietic and cardiac mesoderm during embryonic stem cell differentiation. Proc Natl Acad Sci 102: 13170-13175.

Kraus F, Haenig B, Kispert A. 2001. Cloning and expression analysis of the mouse T-box gene Tbx18. Mech Dev 100: $83-86$.

Kruithof BP, van Wijk B, Somi S, Kruithof-de Julio M, Perez Pomares JM, Weesie F, Wessels A, Moorman AF, van den Hoff MJ. 2006. BMP and FGF regulate the differentiation of multipotential pericardial mesoderm into the myocardial or epicardial lineage. Dev Biol 295: 507-522.

Kubalak SW, Miller-Hance WC, O'Brien TX, Dyson E, Chien KR. 1994. Chamber specification of atrial myosin light chain-2 expression precedes septation during murine cardiogenesis. J Biol Chem 269: 16961-16970.

Kuriyama S, Mayor R. 2008. Molecular analysis of neural crest migration. Philos Trans R Soc Lond B Biol Sci 363: 1349-1362.

Kwee L, Baldwin HS, Shen HM, Stewart CL, Buck C, Buck CA, Labow MA. 1995. Defective development of the embryonic and extraembryonic circulatory systems in vascular cell adhesion molecule (VCAM-1) deficient mice. Development 121: 489-503.

Lage K, Greenway SC, Rosenfeld JA, Wakimoto H, Gorham JM, Segre AV, Roberts AE, Smoot LB, Pu WT, Pereira AC, et al. 2012. Genetic and environmental risk factors in congenital heart disease functionally converge in protein networks driving heart development. Proc Natl Acad Sci 109: 14035-14040.

Lavine KJ, Ornitz DM. 2008. Fibroblast growth factors and Hedgehogs: At the heart of the epicardial signaling center. Trends Genet 24: 33-40.

Lavine KJ, White AC, Park C, Smith CS, Choi K, Long F, Hui CC, Ornitz DM. 2006. Fibroblast growth factor signals regulate a wave of Hedgehog activation that is essential for coronary vascular development. Genes Dev 20: 16511666.

Li P, Cavallero S, Gu Y, Chen TH, Hughes J, Hassan AB, Bruning JC, Pashmforoush M, Sucov HM. 2011. IGF 
T. Brade et al.

signaling directs ventricular cardiomyocyte proliferation during embryonic heart development. Development 138: 1795-1805.

Lim J, Thiery JP. 2012. Epithelial-mesenchymal transitions: Insights from development. Development 139: 3471 3486.

Lints TJ, Parsons LM, Hartley L, Lyons I, Harvey RP. 1993. Nkx-2.5: A novel murine homeobox gene expressed in early heart progenitor cells and their myogenic descendants. Development 119: 969.

Liu N, Olson EN. 2010. MicroRNA regulatory networks in cardiovascular development. Dev Cell 18: 510-525.

Manner J, Perez-Pomares JM, Macias D, Munoz-Chapuli R. 2001. The origin, formation and developmental significance of the epicardium: A review. Cells Tissues Organs 169: $89-103$.

Martinez-Estrada OM, Lettice LA, Essafi A, Guadix JA, Slight J, Velecela V, Hall E, Reichmann J, Devenney PS, Hohenstein P, et al. 2010. Wt1 is required for cardiovascular progenitor cell formation through transcriptional control of Snail and E-cadherin. Nat Genet 42: 89-93.

Martin-Puig S, Wang Z, Chien KR. 2008. Lives of a heart cell: Tracing the origins of cardiac progenitors. Cell Stem Cell 2: 320-331.

Marvin MJ, Di Rocco G, Gardiner A, Bush SM, Lassar AB. 2001. Inhibition of Wnt activity induces heart formation from posterior mesoderm. Genes Dev 15: 316-327.

Merki E, Zamora M, Raya A, Kawakami Y, Wang J, Zhang X, Burch J, Kubalak SW, Kaliman P, Izpisua Belmonte JC, et al. 2005. Epicardial retinoid X receptor $\alpha$ is required for myocardial growth and coronary artery formation. Proc Natl Acad Sci 102: 18455-18460.

Mjaatvedt CH, Nakaoka T, Moreno-Rodriguez R, Norris RA, Kern MJ, Eisenberg CA, Turner D, Markwald RR. 2001. The outflow tract of the heart is recruited from a novel heart-forming field. Dev Biol 238: 97-109.

* Moorman A. 2013. Heart fields and cardiac morphogenesis. Cold Spring Harb Perspect Med doi: 10.1101/cshperspect.a015750.

Moretti A, Caron L, Nakano A, Lam JT, Bernshausen A, Chen Y, Qyang Y, Bu L, Sasaki M, Martin-Puig S, et al. 2006. Multipotent embryonic is $11^{+}$progenitor cells lead to cardiac, smooth muscle, and endothelial cell diversification. Cell 127: 1151-1165.

Motoike T, Markham DW, Rossant J, Sato TN. 2003. Evidence for novel fate of Flk $1^{+}$progenitor: Contribution to muscle lineage. Genesis 35: 153-159.

* Mummery C. 2013. Paradigms for heart cell therapeutics. Cold Spring Harb Perspect Med doi: 10.1101/cshperspect.a013862.

Mummery CL, Zhang J, Ng ES, Elliott DA, Elefanty AG, Kamp TJ. 2012. Differentiation of human embryonic stem cells and induced pluripotent stem cells to cardiomyocytes: A methods overview. Circ Res 111: 344-358.

Musunuru K, Domian IJ, Chien KR. 2010. Stem cell models of cardiac development and disease. Annu Rev Cell Dev Biol 26: 667-687.

Nahirney PC, Mikawa T, Fischman DA. 2003. Evidence for an extracellular matrix bridge guiding proepicardial cell migration to the myocardium of chick embryos. Dev Dyn 227: $511-523$.
Noseda M, Peterkin T, Simoes FC, Patient R, Schneider MD. 2011. Cardiopoietic factors: Extracellular signals for cardiac lineage commitment. Circ Res 108: 129-152.

Olivey HE, Svensson EC. 2010. Epicardial-myocardial signaling directing coronary vasculogenesis. Circ Res 106: 818-832.

Olson EN. 2004. A decade of discoveries in cardiac biology. Nat Med 10: 467-474.

Parmacek MS, Epstein JA. 2009. Cardiomyocyte renewal. N Engl J Med 361: 86-88.

Perez-Pomares JM, de la Pompa JL. 2011. Signaling during epicardium and coronary vessel development. Circ Res 109: $1429-1442$.

Porrello ER, Mahmoud AI, Simpson E, Hill JA, Richardson JA, Olson EN, Sadek HA. 2011. Transient regenerative potential of the neonatal mouse heart. Science 331: $1078-1080$.

Prall OW, Menon MK, Solloway MJ, Watanabe Y, Zaffran S, Bajolle F, Biben C, McBride JJ, Robertson BR, Chaulet H, et al. 2007. An Nkx2-5/Bmp2/Smad1 negative feedback loop controls heart progenitor specification and proliferation. Cell 128: 947-959.

Qian L, Huang Y, Spencer CI, Foley A, Vedantham V, Liu L, Conway SJ, Fu JD, Srivastava D. 2012. In vivo reprogramming of murine cardiac fibroblasts into induced cardiomyocytes. Nature 485: 593-598.

Reese DE, Mikawa T, Bader DM. 2002. Development of the coronary vessel system. Circ Res 91: 761-768.

Reifers F, Walsh EC, Leger S, Stainier DY, Brand M. 2000. Induction and differentiation of the zebrafish heart requires fibroblast growth factor 8 (fgf8/acerebellar). Development 127: 225-235.

Saga Y, Kitajima S, Miyagawa-Tomita S. 2000. Mesp1 expression is the earliest sign of cardiovascular development. Trends Cardiovasc Med 10: 345-352.

Sato A, Scholl AM, Kuhn EN, Stadt HA, Decker JR, Pegram K, Hutson MR, Kirby ML. 2011. FGF8 signaling is chemotactic for cardiac neural crest cells. Dev Biol 354: 18 30.

Schlueter J, Brand T. 2012. Epicardial progenitor cells in cardiac development and regeneration. JCardiovasc Transl Res 5: 641-653.

Schneider VA, Mercola M. 2001. Wnt antagonism initiates cardiogenesis in Xenopus laevis. Genes Dev 15: 304-315.

Scholl AM, Kirby ML. 2009. Signals controlling neural crest contributions to the heart. Wiley Interdiscip Rev Syst Biol Med 1: 220-227.

Schultheiss TM, Burch JB, Lassar AB. 1997. A role for bone morphogenetic proteins in the induction of cardiac myogenesis. Genes Dev 11: 451-462.

Scott IC. 2012. Life before Nkx2.5: Cardiovascular progenitor cells: Embryonic origins and development. Curr Top Dev Biol 100: 1-31.

Senyo SE, Steinhauser ML, Pizzimenti CL, Yang VK, Cai L, Wang M, Wu TD, Guerquin-Kern JL, Lechene CP, Lee RT. 2013. Mammalian heart renewal by pre-existing cardiomyocytes. Nature 493: 433-436.

Showell C, Binder O, Conlon FL. 2004. T-box genes in early embryogenesis. Dev Dyn 229: 201-218. 
Song H, Chung SK, Xu Y. 2010. Modeling disease in human ESCs using an efficient BAC-based homologous recombination system. Cell Stem Cell 6: 80-89.

Srivastava D. 2006. Genetic regulation of cardiogenesis and congenital heart disease. Annu Rev Pathol 1: 199-213.

Sucov HM, Gu Y, Thomas S, Li P, Pashmforoush M. 2009. Epicardial control of myocardial proliferation and morphogenesis. Pediatr Cardiol 30: 617-625.

Torlopp A, Schlueter J, Brand T. 2010. Role of fibroblast growth factor signaling during proepicardium formation in the chick embryo. Dev Dyn 239: 2393-2403.

Tzahor E. 2007. Wnt/ $\beta$-catenin signaling and cardiogenesis: Timing does matter. Dev Cell 13: 10-13.

Tzahor E, Lassar AB. 2001. Wnt signals from the neural tube block ectopic cardiogenesis. Genes Dev 15: 255-260.

van Wijk B, van den Berg G, Abu-Issa R, Barnett P, van der Velden S, Schmidt M, Ruijter JM, Kirby ML, Moorman AF, van den Hoff MJ. 2009. Epicardium and myocardium separate from a common precursor pool by crosstalk between bone morphogenetic protein- and fibroblast growth factor-signaling pathways. Circ Res 105: 431441.

Vincent SD, Buckingham ME. 2010. How to make a heart The origin and regulation of cardiac progenitor cells. Curr Top Dev Biol 90: 1-41.

von Gise A, Zhou B, Honor LB, Ma Q, Petryk A, Pu WT. 2011. WT1 regulates epicardial epithelial to mesenchymal transition through $\beta$-catenin and retinoic acid signaling pathways. Dev Biol 356: 421-431.

Waldo KL, Kumiski DH, Wallis KT, Stadt HA, Hutson MR, Platt DH, Kirby ML. 2001. Conotruncal myocardium arises from a secondary heart field. Development 128: 3179-3188.

Waldo KL, Hutson MR, Ward CC, Zdanowicz M, Stadt HA, Kumiski D, Abu-Issa R, Kirby ML. 2005. Secondary heart field contributes myocardium and smooth muscle to the arterial pole of the developing heart. Dev Biol 281: $78-90$.
Embryonic Heart Progenitors and Cardiogenesis

Weissman IL. 2000. Stem cells: Units of development, units of regeneration, and units in evolution. Cell 100: 157168.

Wu SM, Fujiwara Y, Cibulsky SM, Clapham DE, Lien CL, Schultheiss TM, Orkin SH. 2006. Developmental origin of a bipotential myocardial and smooth muscle cell precursor in the mammalian heart. Cell 127: 1137-1150.

Xu X, Francis R, Wei CJ, Linask KL, Lo CW. 2006. Connexin 43-mediated modulation of polarized cell movement and the directional migration of cardiac neural crest cells. Development 133: 3629-3639.

Yang JT, Rayburn H, Hynes RO. 1995. Cell adhesion events mediated by $\alpha 4$ integrins are essential in placental and cardiac development. Development 121: 549-560.

Yang L, Soonpaa MH, Adler ED, Roepke TK, Kattman SJ, Kennedy M, Henckaerts E, Bonham K, Abbott GW, Linden RM, et al. 2008. Human cardiovascular progenitor cells develop from a $\mathrm{KDR}^{+}$embryonic-stem-cell-derived population. Nature 453: 524-528.

Zaffran S, Kelly RG, Meilhac SM, Buckingham ME, Brown NA. 2004. Right ventricular myocardium derives from the anterior heart field. Circ Res 95: 261-268.

Zamora M, Manner J, Ruiz-Lozano P. 2007. Epicardiumderived progenitor cells require $\beta$-catenin for coronary artery formation. Proc Natl Acad Sci 104: 18109-18114.

Zeisberg EM, Ma Q, Juraszek AL, Moses K, Schwartz RJ, Izumo S, Pu WT. 2005. Morphogenesis of the right ventricle requires myocardial expression of Gata4. J Clin Invest 115: 1522-1531.

Zhou B, Ma Q, Rajagopal S, Wu SM, Domian I, RiveraFeliciano J, Jiang D, von Gise A, Ikeda S, Chien KR, et al. 2008a. Epicardial progenitors contribute to the cardiomyocyte lineage in the developing heart. Nature 454: 109-113.

Zhou B, von Gise A, Ma Q, Rivera-Feliciano J, Pu WT. 2008b. Nkx2-5- and Isl1-expressing cardiac progenitors contribute to proepicardium. Biochem Biophys Res Commun 375: $450-453$. 


\section{$\&_{\mathrm{CSH}}^{\infty} \&$ Cold Spring Harbor

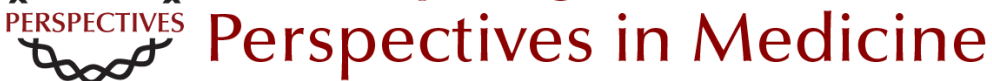

\section{Embryonic Heart Progenitors and Cardiogenesis}

Thomas Brade, Luna S. Pane, Alessandra Moretti, Kenneth R. Chien and Karl-Ludwig Laugwitz

Cold Spring Harb Perspect Med 2013; doi: 10.1101/cshperspect.a013847

Subject Collection The Biology of Heart Disease

The Genetic Basis of Aortic Aneurysm Mark E. Lindsay and Harry C. Dietz

\section{Personalized Genomes and Cardiovascular \\ Disease \\ Kiran Musunuru}

Complex Genetics and the Etiology of Human

Congenital Heart Disease

Bruce D. Gelb and Wendy K. Chung

Genetic Networks Governing Heart Development Ashley J. Waardenberg, Mirana Ramialison, Romaric Bouveret, et al.

Heart Fields and Cardiac Morphogenesis Robert G. Kelly, Margaret E. Buckingham and Antoon F. Moorman

Regenerative Medicine: Transforming the Drug Discovery and Development Paradigm Sotirios K. Karathanasis

Myocardial Tissue Engineering: In Vitro Models Gordana Vunjak Novakovic, Thomas Eschenhagen and Christine Mummery

Pluripotent Stem Cell Models of Human Heart

Disease

Alessandra Moretti, Karl-Ludwig Laugwitz, Tatjana

Dorn, et al.
Cardiac Cell Lineages that Form the Heart Sigolène M. Meilhac, Fabienne Lescroart, Cédric Blanpain, et al.

Synthetic Chemically Modified mRNA (modRNA):

Toward a New Technology Platform for

Cardiovascular Biology and Medicine Kenneth R. Chien, Lior Zangi and Kathy O. Lui

Next-Generation Models of Human Cardiogenesis via Genome Editing

Xiaojun Lian, Jiejia Xu, Jinsong Li, et al.

How to Make a Heart Valve: From Embryonic Development to Bioengineering of Living Valve Substitutes

Donal MacGrogan, Guillermo Luxán, Anita Driessen-Mol, et al.

Insights into the Genetic Structure of Congenital Heart Disease from Human and Murine Studies on Monogenic Disorders Terence Prendiville, Patrick Y. Jay and William T. $\mathrm{Pu}$

Cardiovascular Drug Discovery: A Perspective from a Research-Based Pharmaceutical Company G. Gromo, J. Mann and J.D. Fitzgerald

Genetics and Disease of Ventricular Muscle Diane Fatkin, Christine E. Seidman and Jonathan G. Seidman

Embryonic Heart Progenitors and Cardiogenesis Thomas Brade, Luna S. Pane, Alessandra Moretti, et al.

For additional articles in this collection, see http://perspectivesinmedicine.cshlp.org/cgi/collection/ 